American Journal of Infectious Diseases 5 (4): 282-287, 2009

ISSN 1553-6203

(C) 2009 Science Publications

\title{
C-Reactive Protein and Serum Procalcitonin Levels as Markers of Bacterial Upper Respiratory Tract Infections
}

\author{
${ }^{1}$ Diamantis P. Kofteridis, ${ }^{1}$ George Samonis, ${ }^{2}$ Alexander D. Karatzanis, \\ ${ }^{2}$ Georgios M. Fragiadakis, ${ }^{2}$ Constantinos A. Bourolias, ${ }^{3}$ Sofia Maraki, \\ ${ }^{1}$ John A. Papadakis and ${ }^{2}$ George A. Velegrakis \\ ${ }^{1}$ Department of Internal Medicine, \\ ${ }^{2}$ Department of Otorhinolaryngology, \\ ${ }^{3}$ Department of Clinical Bacteriology, \\ University Hospital of Heraklion, P.O. Box 1352-71110, Heraklion Crete, Greece
}

\begin{abstract}
Problem statement: Upper Respiratory Tract Infections (URTIs) are the most frequent of the community with major social and financial impact. Hence, early and proper diagnosis is of utmost importance. Biomarkers such as the circulating levels of Procalcitonin (PCT) have been shown to be elevated in systemic bacterial infections, but remain relatively low in viral infections and inflammatory diseases and have been suggested as signals for the initiation of antimicrobial therapy. Experience evaluating the value of PCT as a marker of URTIs is limited. Approach: Forty patients with bacterial URTIs were studied in order to assess the role of PCT, measured by using the semi-quantitative test, as bacterial inflammation marker and to compare with other markers, such as C-Reactive Protein (CRP), White Blood Cell (WBC) counts and Polymorphonuclear (PMN) cell counts. Results: In all cases, 22 with tonsillopharyngitis, 10 with peritonsillar abscess and 8 with rhinosinusitis, PCT levels remained below detection limits. On the other hand, serum CRP levels strongly correlated with body temperature, WBC and PMN cell counts. Patients with rhinosinusitis were older than those with peritonsillar abscess, had lower body temperature than those with tonsillopharyngitis and had lower serum CRP levels than patients with either peritonsillar abscess or tonsillopharyngitis. Conclusion: Therefore CRP could be used as a marker to predict the severity of URTIs while PCT, although promising in cases of other severe bacterial infections, did not prove to be suitable for patients with less severe or localized infections, such as URTIs.
\end{abstract}

Key words: Procalcitonin, C-reactive protein, upper respiratory tract infections

\section{INTRODUCTION}

Upper Respiratory Tract Infections (URTIs) are the most frequent infections of the community, with major social and financial impact ${ }^{[1]}$. They represent a heterogeneous group of diseases ranging from common cold to complicated rhinosinusitis and acute otitis media. The main challenge for the physician is to distinguish the uncomplicated cold from cases of streptococcal pharyngitis and secondary bacterial sinusitis and otitis media in order to avoid overprescribing of antibiotics, limit complications, costs and selection of resistant microorganisms. It is estimated that physicians in such cases overprescribe antibiotics by $50 \%{ }^{[2-4]}$.

Among URTIs tonsillopharyngitis, peritonsillar abscess and rhinosinusitis account for a significant number of infections of bacterial origin. The diagnosis is mainly based on clinical criteria, especially in an ENT outpatient office. The most precise way to diagnose a bacterial infection is by culture of the causative agent ${ }^{[5-7]}$. However, a novel approach for confirmation of the bacterial origin of infections and proper selection of antimicrobial therapy is based on the level of biomarkers, specifically Procalcitonin (PCT) ${ }^{[8-15]}$.

Circulating levels of PCT are elevated in systemic bacterial infections but remain relatively low in viral infections and inflammatory diseases ${ }^{[8-15]}$.

Hence, the aim of the current study was to assess the role of PCT as a bacterial inflammation marker in patients with tonsillopharyngitis, rhinosinusitis and peritonsillar abscess and compare it with other markers, such as CRP, White Blood Cells (WBC) and Polymorphonuclear (PMN) cell counts.

Corresponding Author: Diamantis P. Kofteridis, Department of Internal Medicine, University Hospital of Heraklion, P.O. Box 1352-71110, Heraklion, Crete, Greece Tel: (+30) 2810392359 Fax: (+30) 2810392847 
Am. J. Infect. Dis., 5 (4): 282-287, 2009

\section{MATERIALS AND METHODS}

The study was performed prospectively at the University Hospital of Heraklion Crete, Greece, was approved by the Ethics Committee, while consent was obtained by all patients. Subjects were first seen at the ENT outpatient clinic and were treated either as out-or inpatients according to standard protocols.

A total of 40 individuals were enrolled, divided into three groups according to clinical diagnosis: Tonsillopharyngitis $(\mathrm{n}=22)$, peritonsillar abscess $(\mathrm{n}=10)$ and bacterial rhinosinusitis $(\mathrm{n}=8)$.

Diagnosis of tonsillopharyngitis was based on pain and difficulty in swallowing, otalgia, fever $\left(>38.5^{\circ} \mathrm{C}\right)$ accompanied by rigor, change in voice, tender cervical lymph nodes and swollen reddish tonsils with whitish exudate.

Diagnosis of peritonsillar abscess was based on pus, located deep into the tonsillar capsule between the tonsil and the superior constrictor muscle, deviation of the tonsil and uvula, swelling of the soft palate, trismus and drooling. Diagnosis was established by culture of aspiration specimen.

Diagnosis of rhinosinusitis was based on the presence of at least two symptoms, such as nasal blockage or congestion, anterior discharge or post nasal drip, facial pain or pressure and reduction or loss of smell accompanied by endoscopic signs and/or relevant computed tomography findings, according to the criteria of the European rhinosinusitis Committee ${ }^{[16]}$.

All patients were interviewed and a detailed medical history was obtained, including demographic data (age, sex, occupation, residence), medical history, symptoms and use of medication with focus on use of antimicrobials. Body temperature was recorded at the time of initial examination. A full and thorough head and neck physical examination was performed and recorded. Patients were treated as out or in-patients according to the severity of the infection. All patients were immunocompetent, with no concurrent diseases, except for one with bronchial asthma. Antimicrobial treatment was initiated or continued in all patients after the first examination.

Specimens were cultured from all patients, including tonsillar swabs from those with tonsillopharyngitis, aspirated pus from those with peritonsillar abscess and secretions from middle meatus from those with rhinosinusitis. All samples were inoculated onto Columbia blood agar, chocolate agar, MacConkey agar and Sabouraud's agar plates (all media products of Becton Dickinson Diagnostics, Heidelberg, Germany) and incubated in aerobic atmosphere at $36^{\circ} \mathrm{C}$. Additionally, one $\mathrm{CDC}$-anaerobic blood agar plate (bioMérieux, Marcy L' Etoile, France) was inoculated and incubated anaerobically at $36^{\circ} \mathrm{C}$ for $48 \mathrm{~h}$. The identification of pathogens was performed by standard microbiological methods and the API system (bioMerieux, Marcy L' Etoile, France). Susceptibility to antimicrobial agents was determined by the disk diffusion method recommended by the Clinical and Laboratory Standards Institute (CLSI).

Blood samples were obtained from all patients for complete blood count, CRP and PCT. PCT measurement was based on the BRAHMS PCT-Q test, which is an immunochromatografic test for the semiquantitative detection of PCT for diagnosis and control of therapeutic results in cases of microbial infections and sepsis.

Statistical analysis and presentation of results: Values are expressed as median and range. All $p$ values are two-tailed. Correlation was assessed by Spearman's correlation $\left(r_{\mathrm{s}}\right)$. Results between groups were assessed by Mann-Whitney tests. Frequency analysis was assessed by $\chi^{2}$ test, with Yate's correction. A p-value less than 0.05 was regarded as statistically significant.

\section{RESULTS}

The study comprised of 40 patients, 24 male $(60 \%)$ and 16 female (40\%) with a median age of 25 (range: 16-56) years. Fever upon admission was seen in 34 patients (85\%). Among the 40 patients, 10 (25\%) were diagnosed with peritonsillar abscess, all of whom had positive cultures, while $80 \%$ of them had been taking antibiotics for at least one day prior to first examination. Streptococcus spp. were isolated in 4 patients, Fusobacterium necrophorum in 3 patients, while Arcanobacterium haemoliticus, Prevotela loescheii and Haemophilus influenzae were the strains isolated from each of the rest patients with peritonsilar abscesses.

Eight out of 40 patients (20\%) were diagnosed with rhinosinusitis. Among them 2 (25\%) were already taking antimicrobial treatment at the time of first examination. Only 3 out of 8 patients with rhinosinusitis (37.5\%) had a positive culture. The organisms isolated were Escherichia coli, Streptococcus pneumoniae and Staphylococcus epidermidis. The remaining 22 patients (55\%) had tonsillopharyngitis. Among them, 10 $(45.5 \%)$ had a positive culture. Streptococcus pyogenes grew in all of them. Eight patients with tonsillopharyngitis $(36.4 \%)$ were taking antimicrobial therapy at the time of first examination. 
Am. J. Infect. Dis., 5 (4): 282-287, 2009

Table 1: Patient's characteristics

\begin{tabular}{llll}
\hline & $\begin{array}{l}\text { Peritonsillar abscess } \\
(\mathrm{n}=10)\end{array}$ & $\begin{array}{l}\text { Rhinosinusitis } \\
(\mathrm{n}=8)\end{array}$ & $\begin{array}{l}\text { Tonsillopharyngitis } \\
(\mathrm{n}=22)\end{array}$ \\
\hline Age (years) & 22 & $31^{* *}$ & 24 \\
Range & $(16-33)$ & $(23-42)$ & $(17-56)$ \\
Men & 6 & 5 & 13 \\
Percent & -60 & -62.50 & -59.10 \\
Body temperature & 38.2 & 37.6 & $38.5^{*}$ \\
$\left({ }^{\circ} \mathrm{C}\right.$ range $)$ & $(36.8-39.2)$ & $(36.4-38.7)$ & $(36.5-39.6)$ \\
Positive culture & $10^{* *}$ & 3 & 10 \\
Percent & -100 & -37.50 & -45.50 \\
Already & $8^{*}$ & 2 & 8 \\
Receiving & -80 & -25 & -36 \\
antibiotics $(\%)$ & & & \\
CRP $\left(m g ~ \mathrm{~mL}^{-1}\right)$ & 13.9 & $1.77 * *$ & 8.52 \\
range & $(1.20-24.10)$ & $(0.12-9.80)$ & $(0.31-22.60)$ \\
WBC $\left(\mu \mathrm{L}^{-1}\right)$ & 17150 & $11900^{*}$ & 14500 \\
range & $(7700-23500)$ & $(8000-13400)$ & $(7900-25000)$ \\
PMN $\left(\mu \mathrm{L}^{-1}\right)$ & 13969 & $8418^{*}$ & 11427 \\
range & $(5159-19270)$ & $(5200-11500)$ & $(5336-21500)$ \\
\hline
\end{tabular}

CRP: C-Reactive Protein; WBC: White Blood Cell count; PMN: Polymorphonuclear cell count; *: $\mathrm{p}<0.05$; **: $\mathrm{p}<0.01$; All values are expressed as number (\%) or median (range). Between group results were compared by Mann-Whitney test or by $\chi^{2}$ test with Yate's correction, as appropriate

Patients with rhinosinusitis were older than those with peritonsillar abscess $(\mathrm{p}=0.01)$, had lower body temperature than those with tonsillopharyngitis $(\mathrm{p}<0.05)$ and had lower serum CRP levels than patients with either peritonsillar abscess $(\mathrm{p}<0.01)$ or tonsillopharyngitis $(\mathrm{p}<0.01)$. There was no difference in the sex distribution between the 3 groups (Table 1).

Overall 22 patients $(55 \%)$ was not under antimicrobial treatment on initial examination, whereas $11(27.5 \%)$ and $7(17.5 \%)$ had received antibiotics for one and two days prior to examination, respectively. In 23 patients $(57.5 \%)$ a causative microorganism grew from specimens sent for culture. Patients with rhinosinusitis had lower WBC $(\mathrm{p}<0.05)$ and PMN $(\mathrm{p}<0.05)$ counts and CRP serum levels $(\mathrm{p}<0.01)$ than both other groups (Table 1).

Serum CRP levels were significantly correlated with body temperature $\left(\mathrm{r}_{\mathrm{s}}=0.553 ; \mathrm{p}<0.001\right)$, WBC $\left(r_{s}=0.560 ; p<0.001\right), P M N\left(r_{s}=0.594 ; p<0.001\right)$. Body temperature was correlated with WBC $\left(\mathrm{r}_{\mathrm{s}}=0.339\right.$; $\mathrm{p}<0.05)$ and PMN $\left(\mathrm{r}_{\mathrm{s}}=0.367 ; \mathrm{p}<0.05\right)$. In all cases measurement of PCT yielded levels below $0.5 \mathrm{ng} \mathrm{mL}^{-1}$, which is the detectable limit. All patients received antimicrobial therapy after initial examination.

On follow up, performed 1-3 weeks after initial examination, no sequelae were noted and all patients were free of any clinical signs and symptoms of infection.

\section{DISCUSSION}

In the present study we have shown that PCT was not proven to be a marker of bacterial URTIs while,
CRP could be used as a marker of severity of these type of infections.

URTIs are common with substantial financial and social costs ${ }^{[1]}$. Though mainly viral in origin, their etiologic diagnosis is seldom and the pathogen remains unidentified in many cases ${ }^{[5-7]}$. The clinical diagnosis of a bacterial URTI is a challenge even for the most experienced physician. Hence, several diagnostic markers have been tested for their efficacy to accurately distinguish bacterial from non-bacterial disease. These markers include WBC count and other biomarkers such as troponin, B-type Natriuretic Peptide (BNP), Nterminal proBNP, CRP, PCT, cholesterol and coagulation related markers ${ }^{[13]}$. The goal is to limit the use of antimicrobials and the concurrent development of bacterial resistance. Additionally there is always need for the physician to predict whether a URTI may become complicated, especially in susceptible populations, such as children and the elderly.

Among the proposed markers for rapid distinction between bacterial and non-bacterial etiology, PCT is thought to be the most promising for infections of the upper respiratory tract ${ }^{[12-15]}$. There are four available commercial kits for the measurement of $\mathrm{PCT}^{[17]}$. The semi-quantitative test (BRAHMS PCT-Q), was used in the present study because it is cheap, easy, suitable for office procedures and fast, since results are available in less than an hour. The BRAHMS PCT-Q test has 90$92 \%$ sensitivity and $92-98 \%$ specificity and detects PCT levels above $0.5 \mathrm{ng} \mathrm{mL}^{-1[15]}$.

PCT is a protein of 116 amino-acids, with molecular weight of $13 \mathrm{KDa}$, discovered in 1975 by Moya et al. ${ }^{[18]}$, as a prohormone of calcitonin, produced by C-cells of the thyroid. Experimental data from both in vivo and in vitro studies have shown that not only bacterial endotoxins, but also various other mediators, such as TNF $\alpha$, IL-2, IL-6 and phytohemagglutinin induce PCT production ${ }^{[19,20]}$. After administration of endotoxin, TNF rises first, reaching its peak in $90 \mathrm{~min}$, followed by IL- 6 with its peak at $180 \mathrm{~min}$, while PCT reacts only after 3-6 h later ${ }^{[21]}$. Due to their long halflife, PCT levels culminate $12-48 \mathrm{~h}$ after the administration of endotoxin. The probable sites of PCT production in inflammation are the neuroendocrine cells in the lungs or intestine, when stimulated by endotoxin or inflammatory cytokines. Once induced, PCT acts as a chemokine in the area of production, attracting further monocytes, lasting for a few hours. Later on, parenchymatous cells are a major source for PCT during sepsis, but only when they come in contact with activated monocytes ${ }^{[21]}$.

The biological activity of PCT has significant influence on the course of systemic inflammation and 
sepsis. The mortality of hamsters decreased when calcitonin precursors were neutralized ${ }^{[22]}$. On the other hand sepsis, infections, prolonged ICU treatment and poor outcome were more frequent in patients with initially high PCT $\left(>1 \mathrm{ng} \mathrm{mL}^{-1}\right)$. Higher PCT concentrations correlate with severe trauma and a higher frequency of complications, whereas increases of CRP showed no positive correlation in trauma patients $^{[22]}$. Long before PCT, WBC count has been used as an indicator of both infection and its severity. WBC elevation, while worrisome, is neither sensitive nor specific indicator of bacteremia and other serious bacterial infection ${ }^{[23]}$. PMN cell count is a fraction of WBC's and is considered to be a more accurate marker of bacterial infection.

CRP is an acute phase protein that quickly rises in the face of infection. First was discovered by Tillet and Francis in 1930, in patients infected with $S$. pneumoniae ${ }^{[24]}$. It appears to be produced by hepatocytes within 4-6 h after onset of tissue injury or inflammation, doubling every $8 \mathrm{~h}$, before peaking at around $36 \mathrm{~h}$. Its half-life is short $(4-8 \mathrm{~h})^{[24-26]}$. CRP is synthesized in response to IL-6, which is produced not only in infection, but also in other types of inflammation $^{[27]}$. It binds to polysaccharides in pathogens, thus activating the classical complement pathway.

PCT and CRP have been used as markers for distinguishing bacterial from viral infections ${ }^{[10,12,22]}$. Based on data from a meta-analysis Simmon et al. ${ }^{[28]}$ have found that PCT as a marker has a sensitivity of $92 \%$ and specificity of $73 \%$, whereas CRP a sensitivity of $86 \%$ and specificity of $70 \%$. This means that when a bacterial infection is suspected, measurement of PCT would be the most accurate way of verification.

In the present study patients with bacterial URTIs, were enrolled. Usual clinical criteria were used for the diagnosis. In all cases measurement of PCT yielded levels below $0.5 \mathrm{ng} \mathrm{mL}$, which is the lowest concentration that can be traced.

Few studies exist in the literature regarding URTIs and PCT levels. Elsammak et al. ${ }^{[29]}$ studied PCT and CRP in children with tonsillopharyngitis, using the PCT LUMItest. They found that median levels of PCT in children with Streptococcal tonsillopharyngitis compared to non bacterial tonsillopharyngitis were 0.374 and $0.105 \mathrm{ng} \mathrm{mL}^{-1}$ respectively PCT also had a greater sprcificity than CRP for detection of bacterial tonsillopharyngitis.

All patients in our series had PCT levels below $0.5 \mathrm{ng} \mathrm{mL}^{-1}$. The low levels of PCT could be attributed to two main reasons. First, blood samples might have been taken later than the peak of PCT, which is 6-8 h after the onset of infection, while $48 \mathrm{~h}$ later PCT falls below $1 \mathrm{ng} \mathrm{mL}^{-1}$, especially when antibiotics have already been administered, as in many of our cases (11 out of 23$)^{[30]}$. Second, sensitivity of the PCT-Q test in localized infections of moderate severity such as URTIs is usually lower, compared to patients with generalised infections and positive blood cultures. Therefore, subtle elevations of circulating PCT, are not detected $^{[30]}$.

It is of interest that even in peritonsillar abscess cases, a most severe infection compared to tonsillopharyngitis and rhinosinusitis, PCT levels were below detection limit. On the other hand, WBC, PMN, CRP and body temperature were more elevated in this group than in the others. The fact that use of the semi-quantitative method of PCT measurement in URTI's in the office setting did not prove useful, comes in agreement with the conclusion of the study of Korppi et al. ${ }^{[31]}$ who measured PCT using the LUMI test procalcitonin kit in children with Community Acquired Pneumonia (CAP).

We found a correlation of CRP with body temperature, with higher fever resulting in higher CRP levels. There was also a strong correlation between CRP and WBC and PMN counts, which was anticipated. CRP was found to be more elevated in cases of peritonsillar abscess $(\mathrm{p}<0.01)$, ranging from 1.2-24.1 $\mathrm{mg} \mathrm{mL}^{-1}$, whereas in tonsillopharyngitis CRP levels were somewhat lower. Therefore CRP could be used as a marker to predict the severity as well as any sequelae of URTI's, although a double blind study is needed to confirm this finding. Stolz et al. ${ }^{[11]}$ have found that when the cutoff value of CRP for bacterial lower respiratory tract infections was set to $50 \mathrm{mg} \mathrm{mL}^{-1}$ sensitivity was $94 \%$ and specificity $72 \%$.

A limitation of the present study was that the bacterial origin of URTIs, although clinically strongly suspected, was proven only in $57.5 \%$ of patients studied. The main reason which explains why a negative culture was obtained in nearly half of our patients is that $45 \%$ of them had already been receiving antibiotics on the day of the initial examination.

\section{CONCLUSION}

PCT, although promising in cases of critically ill patients, did not prove to be diagnostic for those with less severe or localized infections, such as URTI's. In contrast, CRP levels were much more accurate markers for bacterial URTIs. It is clear that further investigation is needed to determine the usefulness of PCT in the field of infectious diseases. 


\section{ACKNOWLEDGMENT}

Declaration of interest: The researchers declare that they have no competing interests.

\section{REFERENCES}

1. Goetzel, R.Z., K. Hawkins, R.J. Ozminkowski and S. Wang, 2003. The health and productivity cost burden of the 'top 10' physical and mental conditions affecting six large US employers in 1999. J. Occup. Environ. Med., 45: 5-14. http://www.ncbi.nlm.nih.gov/pubmed/12553174

2. Dowell, S.F. and B. Schwartz, 1997. Resistant pneumococci: Protecting patients through judicious use of antibiotic. Am. Fam. Physician., 55: 1647-1654. http://www.ncbi.nlm.nih.gov/pubmed/9105195

3. Gonzales, R., J.F. Steiner and M.A. Sande, 1997. Antibiotic prescribing for adults with colds, upper respiratory tract infections and bronchitis by ambulatory care physicians. J. Am. Med. Assoc., 278: 901-904.

http://www.ncbi.nlm.nih.gov/pubmed/9302241

4. Schito, G.C., E.A. Debbia and A. Marchese, 2000. The evolving threat of antibiotic resistance in Europe: New data from the Alexander project. J. Antimicrob. Chemother., 46: 3-9. http://www.ncbi.nlm.nih.gov/pubmed/10997593

5. Gwaltney, J.M. Jr., 2005. The Common Cold. In: Principles and Practice of Infectious Diseases, Mandell G.L., J.E. Bennett and R. Dolin (Eds.), 6th Edn., Churchill Livingston, New York, ISBN: 10: 0443066434, pp: 747-752.

6. Bisno, A.L., 2005. Pharyngitis. In: Principles and Practice of Infectious Diseases, Mandell, G.L., R.G. Douglas and J.E. Bennet (Eds.), 6th Edn., Churchill Livingston, New York, USA., ISBN: 10: 0443066434, pp: 752-758.

7. Gwaltney Jr., J.M., 2005. Sinusitis In: Principles and Practice of Infectious Diseases, Mandell, G.L., R.G. Douglas and J.E. Bennet (Eds.), 6th Edn., Churchill Livingston, New York, USA., ISBN: 10: 0443066434, pp: 772-782.

8. Verheij, T.J., J. Hermans and J.D. Mulder, 1994. Effects of doxycycline in patients with acute cough and purulent sputum: A double blind placebo controlled trial. Br. J. Gen. Pract., 44: 400-404. http://www.pubmedcentral.nih.gov/articlerender.fc gi? artid=1238988

9. Saint, S., S. Bent, E. Vittinghoff and D. Grady, 1995. Antibiotics in chronic obstructive pulmonary disease exacerbations. A meta-analysis. J. Am. Med. Assoc., 273: 957-960.

http://www.ncbi.nlm.nih.gov/pubmed/7884956
10. Meisner, M., 2005. Biomarkers of sepsis: Clinically useful? Curr. Opin. Crit. Care, 11: 473-480. http://www.ncbi.nlm.nih.gov/pubmed/16175035

11. Stolz, D., M. Christ-Crain, M.M. Gencay, R. Bingisser and P.R. Huber et al., 2006. Diagnostic value of signs, symptoms and laboratory values in lower respiratory tract infection. Swiss Med. Wkly., 136: 434-440. http://www.ncbi.nlm.nih.gov/pubmed/16862463

12. Assicot, M., D. Gendrel, H. Carsin, J. Raymond, J. Guilbaud and C. Bohuon, 1993. High serum Procalcitonin concentrations in patients with sepsis and infection. Lancet, 341: 515-518. http://www.ncbi.nlm.nih.gov/pubmed/8094770

13. Muller, B., K.L. Becker, H. Schächinger and P.R. Rickenbacher et al., 2000. Calcitonin precursors are reliable markers of sepsis in a medical intensive care unit. Crit. Care Med., 28: 977-983.

http://www.ncbi.nlm.nih.gov/pubmed/10809269

14. Dandona, P., D. Nix, M.F. Wilson, A. Aljada and J. Love et al., 1994. Procalcitonin increase after endotoxin injection in normal subjects. J. Clin. Endocrinol. Metab., 79: 1605-1608. http://www.ncbi.nlm.nih.gov/pubmed/7989463

15. Christ-Crain, M., D. Jaccard-Stolz, R. Bingisser, M.M. Gencay, P.R. Huber and M. Tamm et al., 2004. Effect of procalcitonin-guided treatment on antibiotic use and outcome in lower respiratory tract infections: Cluster-randomised, single-blinded intervention trial. Lancet, 363: 600-607. http://www.ncbi.nlm.nih.gov/pubmed/14987884

16. Rhinosinusitis Task Force Committee, 1997. Report of the rhinosinusitis task force committee meeting. Alexandria, Virginia, August 17, 1996. Otolaryngol. Head Neck Surg., 117: S1-68. http://www.ncbi.nlm.nih.gov/pubmed/9380416

17. Muller, B. and C. Prat, 2006. Markers of acute inflammation in assessing and managing lower respiratory tract infections: Focus on procalcitonin. Clin. Microbiol. Infect., 12: 8-16. DOI: 10.1111/j.1469-0691.2006.01654.x

18. Moya, F., A. Nieto and J.L.R. Candella, 1975. Calcitonin biosynthesis: Evidence for a precursor. Eur. J. Biochem., 55: 407-413. DOI: 10.1111/j.1432-1033.1975.00407.pp.x

19. Nijsten, M.W., P. Olinga and H.J. Hoekstra, 2001. In vitro and in vivo stimulation of procalcitonin by TNF $\alpha$ and IL-6. J. Anästhes Intensiv. Ther., 2: 58-60. http://www.pabstpublishers.de/Medizin/med\%20Z eitschriften/jai/2001-2/index2.htm 
20. Oberhoffer, M., I. Stonans, S. Russwurm, E. Stonane, H. Vogelsang and U. Junker et al., 1999. Procalcitonin expression in human peripheral blood mononuclear cells and its modulation by lipopolysaccharides and sepsis-related cytokines in vitro. J. Lab. Clin. Med., 134: 49-55. http://www.ncbi.nlm.nih.gov/pubmed/10402059

21. Maruna, P., K. Nedelnikova and R. Gurlich, 2000. Physiology and genetics of procalcitonin. Physiol. Res., 49: S57-S61. http://www.ncbi.nlm.nih.gov/pubmed/10984072

22. Meisner, M., H. Adina and J. Schmidt, 2006. Correlation of procalcitonin and C-reactive protein to inflammation, complications and outcome during the intensive care unit course of multipletrauma patients. Crit. Care, 10: 1-10. http://www.ncbi.nlm.nih.gov/pubmed/16356205

23. Hsiao, A.L. and M.D. Baker, 2005. Fever in the new millennium: A review of recent studies of markers of serious bacterial infection in febrile children. Curr. Opin. Pediatr., 17: 56-61. http://www.ncbi.nlm.nih.gov/pubmed/15659965

24. Jaye, D.L. and K.B. Waites, 1997. Clinical applications of C-reactive protein in pediatrics. Pediatr. Infect. Dis. J., 16: 746-747. http://www.ncbi.nlm.nih.gov/pubmed/9271034

25. Du Clos, T.W., 2000. Function of C-reactive protein. Ann. Med., 32: 274-278. http://www.ncbi.nlm.nih.gov/pubmed/10852144

26. Fraunberger, P., Y. Wang, E. Holler, K.G. Parhofer, D. Nagel, A.K. Walli and D. Seidel, 2006. Prognostic value of interleukin 6, procalcitonin and C-reactive protein levels in intensive care unit patients during first increase of fever. Shock, 26: $10-12$.

http://www.ncbi.nlm.nih.gov/pubmed/16783191
27. Nylen, E.S., K.T. Whang, R.H. Snider, P.M. Steinwald, J.C. White and K.L. Becker, 1998. Mortality is increased by procalcitonin and decreased by an antiserum reactive to procalcitonin in experimental sepsis. Crit. Care Med., 26: 1001-1006. http://www.ncbi.nlm.nih.gov/pubmed/9635646

28. Simon, L., F. Gauvin, D.K. Amre, P. Saint-Louis and J. Lacroix, 2004. Serum procalcitonin and Creactive protein levels as markers of bacterial infection: A systematic review and meta-analysis. Clin. Infect. Dis., 39: 206-217. http://www.ncbi.nlm.nih.gov/pubmed/15307030

29. Elsammak, M., H. Hanna, A. Ghazal, F.B. Edeen and M. Kandil, 2006. Diagnostic value of serum procalcitonin and C-reactive protein in Egyptian children with streptococcal tonsillopharyngitis. Pediatr. Infect. Dis. J., 25: 174-176. http://www.ncbi.nlm.nih.gov/pubmed/16462299

30. Christ-Crain, M. and B. Muller, 2005. Procalcitonin in bacterial infections-hype, hope, more or less? Swiss Med. Wkly., 135: 451-460. http://www.ncbi.nlm.nih.gov/pubmed/16208582

31. Korppi, M., S. Remes and T. Heiskanen-Kosma, 2003. Serum procalcitonin concentrations in bacterial pneumonia in children: A negative result in primary healthcare settings. Pediatr. Pulmonol., 35: 56-61. http://www.ncbi.nlm.nih.gov/pubmed/12461740 